Artigos

Volume 11 - $2021 \mid$ n. 20

\title{
O Direito à Educação no Brasil e seu Financiamento: estado da arte de 1988 a 2018
}

\author{
Cleiton de Oliveira \\ Universidade Estadual de Campinas (UNICAMP), Campinas/SP - Brasil
}

\section{Resumo}

O artigo tem como objetivo realizar um estado da arte referente à produção científica no Brasil de teses de doutorado e dissertações de mestrado que constam no banco de dados da Coordenação de Aperfeiçoamento de Pessoal do Nível Superior (CAPES), de 1988 a 2018, sobre direito à educação e sua interface com o financiamento da área, bem como analisar os desdobramentos do descompasso entre a garantia legal e sua materialização. Para tanto, foram analisadas 113 produções. Verificou-se a ampliação no número de trabalhos e de assuntos abordados, a necessidade de mais recursos financeiros, a ausência de estudos sobre determinados aspectos bem como a não continuidade de políticas educacionais.

Palavras-chave: Direito à Educação. Financiamento da Educação. Estado da Arte.

\section{The Right to Education in Brazil and its Financing: state of the art}

\section{from 1988 to 2018}

\begin{abstract}
The article aims to accomplish a state of the art related to scientific production in Brazil of doctoral thesis and master's dissertations, which are included in the database of the Coordination for the Improvement of Higher Education Personnel (CAPES), from 1988 to 2018, on the right to education and its interface with the financing of the area as well as analyzing the consequences of the discrepancy between the legal guarantee and its materialization. For that, 113 productions were analyzed. There was an increase in the number of papers and subjects dealt with, the need for more financial resources, the lack of studies on certain aspects, as well as the non-continuity of educational policies.
\end{abstract}

Keywords: Right to Education. Financing of Education. State of the Art. 
O Direito à Educação no Brasil e seu Financiamento

\section{Introdução}

A Constituição Federal de 1988 assegurou a titularidade do direito à educação (Art. $6^{\circ}$ ). Tal assertiva "[...] significa, em outros termos, que ela foi positivada dentro de uma Constituição e, portanto, passa a fazer parte do estatuto de um Estado Nacional" (CURY, 2014, p. 1055.). Estabeleceu-se, ainda, que é direito público subjetivo o acesso ao ensino público gratuito (Art. 208, VII, $\S 2^{\circ}$ ), gratuidade esta garantida inicialmente no ensino fundamental, posteriormente alterada pela Emenda Constitucional $n^{\circ} 59 / 2009$, na educação básica assegurada dos 4 aos 17 anos bem como aos de que a ela não tiveram acesso nessa idade (Art. 208, I).

A organização do ensino, conforme a Constituição Federal, se dá sob a égide da Lei de Diretrizes e Bases da Educação Nacional, sendo esta de competência privativa da instância federal (Art. 22). Ainda sobre o assunto, a Carta Magna afirma: compete à União, Estados e Distrito Federal legislar de maneira concorrente em relação à "educação, cultura, ensino e desporto" (Art. 24, IX); estabeleceram-se também as competências comuns entre as esferas de governo em proporcionar os meios de acesso, dentre outros, à educação e cultura (Art. 23, V); inovou-se ao possibilitar a existência de sistemas municipais de ensino; registrou-se a necessidade do regime de colaboração entre as instâncias de governo e indicaram-se os níveis de atuação prioritária de cada uma delas (Art. 211).

Para a manutenção e desenvolvimento do ensino, a Constituição Federal manteve o instituto da vinculação orçamentária obrigatória, aumentando para $18 \%$ a contribuição da União e mantendo os $25 \%$ para as demais instâncias administrativas de governo. É de se registrar que essa vinculação fora introduzida na Constituição de 1934 e mantida nas demais dos períodos democráticos, suprimida nas Cartas de 1937 e na de 1967, foi restabelecida apenas em relação ao nível municipal na Emenda Constitucional de 1969; em 1983 foi aprovada a Emenda Calmon, sendo a vinculação orçamentária restabelecida para todas as instâncias de governo, regulamentada em 1985 e entrando em vigor no exercício de 1986. Acresce que a política de fundos criou subvinculação, inicialmente para o ensino fundamental pela Emenda Constitucional $n^{\circ} 14 / 1996$, posteriormente para o ensino básico pelas Emendas Constitucionais $n^{\circ}$ 53/2006 e $n^{\circ}$ 108/2020. A Emenda Constitucional $n^{\circ}$ 95/2016 instituiu o Novo Regime Fiscal, estabelecendo limites para as despesas primárias da Educação e de outras áreas, assim os recursos que podem ser alocados comprometem a qualidade e a ampliação de serviços (CURY, 2018; OLIVEIRA; SILVA, 2018).

Passados 30 anos da promulgação da Constituição Federal, o presente artigo faz parte de uma pesquisa ${ }^{1}$ em desenvolvimento que tem como objetivo inventariar a produção científica no Brasil, em teses de doutorado e dissertações de mestrado, no período de 1988 a 2018, sobre direito à educação e sua interface com diferentes áreas, bem como analisar os desdobramentos do descompasso entre a garantia legal e sua materialização. As áreas que fazem interface, arroladas na pesquisa, são: avaliação, currículo, educação infantil, educação integral, exigibilidade do direito à educação, financiamento da educação, gestão educacional, legislação, planejamento educacional e privatização. No caso deste artigo, serão analisados os trabalhos sobre o direito à educação e o financiamento da área.

1 Pesquisa Direito à Educação no Brasil: o estado da arte de 1988 a 2018. 
O artigo está composto por uma introdução, três seções e um apêndice. Em um primeiro momento, são apresentadas as bases teóricas e técnicas para a realização da pesquisa; em seguida, são arrolados, analisados e categorizados os dados encontrados no levantamento; no terceiro momento, são apresentadas reflexões gerais sobre o trabalho realizado; por último é inserido, como apêndice, a relação das produções analisadas.

\section{Sobre a Pesquisa}

A pesquisa dos textos das teses e dissertações foi feita no Banco de Dados da Coordenação de Aperfeiçoamento de Nível Superior (CAPES), a partir do descritor "direito à educação", obtendo 1473 títulos. Em seguida, foi associado o termo "direito a educação" AND "financiamento", resultando em 113 trabalhos. A instabilidade do sistema levou à necessidade de conferências e revisões, levantamento dificultado uma vez que, a partir de 2014, o material foi migrado para a Plataforma Sucupira ${ }^{2}$. Do total de trabalhos selecionados, 84, correspondentes a $74,34 \%$, continham resumos completos disponíveis para downloads, enquanto 29 , equivalentes a $26,66 \%$, não se encontravam nessa condição.

As informações foram transcritas, quando disponíveis, em planilha Excel conforme os seguintes dados: ano de defesa, autoria, título do trabalho, tema, texto (link), grau de formação (mestrado acadêmico, mestrado profissional ou doutorado), orientador(a), banca, instituição, tipo de instituição (pública ou particular, esta com ou sem fins lucrativos), agência de financiamento, resumo, palavras-chave, objetivos, referencial teórico, metodologia, resultados e observações gerais. No presente artigo não nos deteremos na análise das bancas, tendo em vista a indisponibilidade em mais de um quarto dos trabalhos.

A classificação por subtemas mostrou-se complexa, uma vez que só o título do trabalho nem sempre se mostrou suficiente para essa tarefa. Alguns títulos são vagos e ensejam mais de uma interpretação; houve, por exemplo o caso de dois trabalhos com o mesmo título, embora tratassem de subtemáticas diferentes. Assim, para a classificação foi necessário consultar as palavras-chave e o resumo, havendo alguns casos, raros na realidade, que obrigaram a uma consulta ao próprio texto.

O presente estudo tem o caráter de uma revisão das publicações sobre as temáticas citadas, perfilado aos estudos que se dedicam a inventariar o estado do conhecimento ou estado da arte. Esses estudos procuram mapear como determinada temática é tratada ao longo de um tempo definido, categorizando-a e discutindo seus vários aspectos (FERREIRA, 2002). A visão de conjunto desses estudos "[...] permitem a compreensão do movimento da área, sua configuração, propensões teóricas metodológicas, (e) análise crítica indicando tendências, recorrências e lacunas" (VOSGERAU; ROMANOWSKI, 2014, p. 167). As pesquisas que se valem do estado da arte revelam "os temas, subtemas e conteúdos priorizados [...] mostram que alguns temas são quase totalmente silenciados" (ROMANOWSKI; ENS, 2006, p. 45), enfim, concorrem para a sistematização de conhecimentos e para balizar pesquisadores. Sem a pretensão de esgotar o assunto, são apresentados a seguir estudos sobre o estado da arte nas subtemáticas pesquisadas.

Um dos primeiros estudos publicados sobre estado da arte em política e gestão da educação no Brasil, referente a publicações de 1991 a 1997, coordenado por Wittmann e

2 O levantamento das Teses e Dissertações foi realizado pelos bolsistas vinculados ao projeto de pesquisa. 
Gracindo (2001), classificou a produção do período em 10 categorias. Machado e Oliveira (2001, p. 60) se encarregaram da temática Direito à Educação e Legislação do Ensino; a primeira, que se relaciona mais de perto ao artigo, registrou como subcategorias: a) Direito à Educação e construção da cidadania; b) Combate à exclusão do acesso à educação, e c) Educação para os Direitos Humanos e/ou cidadania.

A categoria financiamento da educação, na referida publicação, foi analisada por Velloso (2001). O autor classificou os trabalhos nos seguintes tópicos: avaliação institucional, despesas com manutenção e desenvolvimento do ensino, financiamento na legislação e análise de propostas de políticas das agências internacionais. Reconhece-se que estão pouco presentes, dentre outros, estudos sobre os seguintes assuntos: salário-educação, clientelismo no financiamento, convênios com escolas privadas e governos estaduais/municipais, custo aluno e Fundo de Manutenção e Desenvolvimento do Ensino Fundamental e de Valorização do Magistério (FUNDEF).

Outros estudos sobre estado da arte em financiamento da educação foram publicados posteriormente. Dentre esses, sem a intenção de esgotar o levantamento, podem ser citados: Gomes, Carnielli, Jesus e Leal (2007) analisaram a literatura sobre financiamento da educação em livros, artigos e relatórios técnicos, na área educacional, econômica e legislativa, referentes ao período de 1988 a 2004; Santos (2013) analisou livros e artigos sobre a temática, estes em publicações classificadas como A1, A2, B1 e B2, no Qualis Periódicos CAPES - 2008, publicados de 1996 a 2010; Davies (2014) apresentou um levantamento bibliográfico sobre financiamento de educação brasileira, referente ao período de 1988 a 2014; foram arrolados 1123 textos, compreendendo livros, capítulos de livros, dissertações de mestrado, teses de doutorado e artigos em periódicos acadêmicos.

Stremel, Tello e Mainardes (2014) apresentaram um levantamento bibliográfico sobre produções teóricas e epistemológicas de na área de política educacionais elaborado a partir da Biblioteca Temática da ReLePe - Red Latinoamericana de Estudios Epistemológicos; foram catalogados 198 textos categorizados em 7 eixos, dentre estes o terceiro refere-se às metodologias para a análise de políticas educacionais.

Jacomini e Cruz (2019, p. 655) analisaram teses e dissertações no "[...] campo acadêmico das políticas educacionais, na temática específica financiamento da educação", defendidas no período de 2000 a 2010, em Programas de Pós-graduação em Educação que obtiveram no mínimo nota 5, no triênio 2007-2009. Foram apresentados 56 trabalhos, de 19 programas stricto sensu, que preencheram os citados requisitos, sendo analisadas as características gerais dessas produções bem como inventariados "[...] os principais referenciais que contribuíram para a constituição desse campo de pesquisa nos anos 2000" (JACOMINI; CRUZ, 2019, p. 655). A identificação dos trabalhos foi apresentada em apêndice ao texto.

\section{Análise dos Dados}

Foram selecionadas 113 produções no período em estudo, destas, 75 (66,38\%) foram dissertações de mestrado acadêmico, 29 (25,66\%) teses de doutorado e 9 (7,96\%) dissertações de mestrado profissional. Foram produzidas em Cursos de Pós-Graduação em Educação 80 trabalhos (70,80\%); 33 (29,20\%) foram desenvolvidos nos seguintes cursos: Direito (18 trabalhos), Direito Político e Econômico (2), Transporte (2) e com 1 trabalho os 
O Direito à Educação no Brasil e seu Financiamento

Programas de Administração, Direito Econômico e Desenvolvimento, Direito Internacional, Direito Público e Economia, Economia, História, Política Pública e Desenvolvimento, Políticas Sociais e Cidadania, Política Social, Psicologia e Saúde. Assim, a temática foi abordada em variados aspectos em Programas de Pós-graduação de diferentes áreas.

O número total de trabalhos encontrados e respectivas caracterizações divergem de outras pesquisas em virtude de instabilidade do sistema ao longo do tempo, da migração de dados de uma plataforma para outra, de Programas de Pós-graduação que foram extintos e/ou não registraram toda sua produção bem como dos descritores empregados na busca ${ }^{3}$.

O primeiro trabalho selecionado foi defendido em 1998; nos 3 anos seguintes não houve outros registros, sendo encontrados 2 trabalhos em 2002; deste ano em diante, ininterruptamente, constatou-se a existência de trabalhos sobre a temática. A primeira tese de doutorado é de 2004, depois foram registradas de 2008 a 2011 e, posteriormente, de 2015 a 2018. Os trabalhos de mestrado profissional foram defendidos a partir de 2012, sendo registrados nos anos seguintes, exceto em 2016.

O Gráfico 1 apresenta a distribuição dos trabalhos por períodos.

Gráfico 1 - Número de teses e dissertações por período

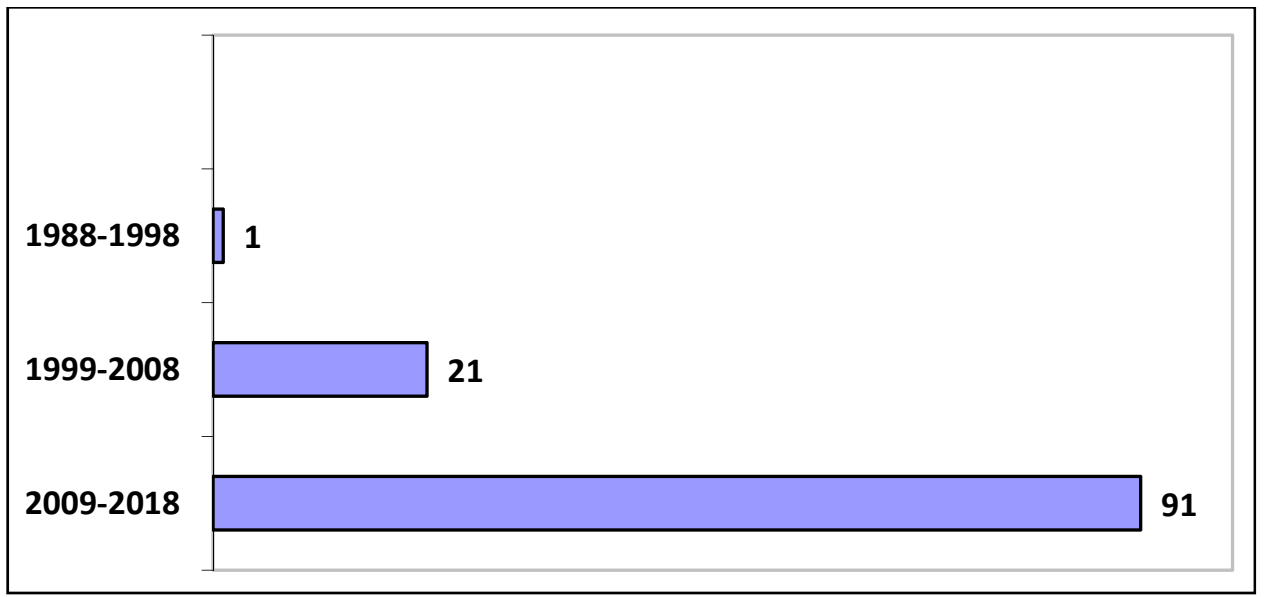

Fonte: Elaboração do Autor.

No primeiro período foi registrado um único trabalho, já no decênio seguinte foram 21 trabalhos e, no último decênio, 91. Além de outros possíveis motivos, esse crescimento assim se explica: pela ampliação do número de Programas de Pós-graduação; pela exigência de titulação para o exercício do magistério superior; pela importância que a questão orçamentária da vinculação obrigatória para a educação assumiu nos orçamentos públicos; pelas discussões nas elaborações e tramitações de políticas para a área.

Os trabalhos foram desenvolvidos nos seguintes tipos de instituições: $108 \mathrm{em}$ universidades, 4 em centros universitários e 1 em órgão federal (IPEA - Instituto de Pesquisa Econômica Aplicada). Nas instituições públicas, foram registrados 57 trabalhos nas federais e 27 nas estaduais; 29 trabalhos foram registrados nas instituições particulares, sendo 24 nas

3 No presente trabalho, a escolha dos descritores está relacionada aos objetivos da pesquisa, que teve como eixo o direito à educação e o seu financiamento. A determinação de descritores norteia a seleção dos trabalhos; Jacomini e Cruz (2019, p. 655), por exemplo, na pesquisa sobre o financiamento da educação, desenvolveram os estudos "com base num conjunto de palavras-chave pré-estabelecido" relacionado à temática. Esta é uma razão, além de eventuais outras, que explica as diferenças em relação ao material selecionado pelas autoras e a presente pesquisa. 
sem fins lucrativos e 5 naquelas com fins lucrativos. Evidenciou-se dessa maneira o protagonismo da rede pública na formação de pós-graduados, com 84 trabalhos $(74,34 \%)$, enquanto a particular se encarregou de 29 (25,66\%).

A Universidade de São Paulo (USP) foi a universidade com maior número de trabalhos, apresentando 19 em sua sede em São Paulo e 1 no campus de Ribeirão Preto; em segundo lugar, com 5 trabalhos, estão a PUC de Minas Gerais, a Universidade Federal do Paraná e a UnB; a seguir, com 4 trabalhos cada uma, as universidades federais do Ceará, de Goiás, do Piauí e do Rio Grande do Sul; com 3 trabalhos, as federais de Juiz de Fora, de Minas Gerais e do Pará, além da Católica de Brasília e da Presbiteriana Mackenzie; com 2 trabalhos, aparecem as federais do Amazonas, do Espírito Santo, a Fluminense, da Paraíba, de Pernambuco e de São Paulo, além da Estadual do Rio de Janeiro; 33 outras instituições apresentaram 1 trabalho cada uma.

É reduzido o número de bolsas declaradas em relação ao total de concluintes, sendo 12 $(16,00 \%)$ para o mestrado acadêmico, $1(11,11 \%)$ para o mestrado profissional e $9(31,03 \%)$ para o doutorado. A CAPES foi a responsável pelo maior número de bolsas, tendo ofertado 9 para o mestrado e 8 para o doutorado, o CNPq foi responsável por 3 bolsas, as FAPs (Fundações de Amparo à Pesquisa) também por 3, sendo 2 do Estado de Minas Gerais e 1 do Estado de Mato Grosso e o PADES (Programa de Apoio à Docência do Ensino Superior) 1 bolsa. Das bolsas de mestrado, uma foi para o mestrado acadêmico de Psicologia e as demais para Educação; no doutorado foram 5 bolsas para a Educação e 4 para os Programas de Direito, Política Social, Psicologia e Transporte.

O levantamento das orientações revelou que Nalu Farenzena (UFRGS) foi a docente com maior número de orientações, sendo responsável por 4 pós-graduados; com 3 orientações, os docentes Rosana Evangelista Cruz (UFPI), Rosângela Gavioli Prieto (USP) e Rubens Camargo Barbosa (USP); com 2 orientações, as professoras Adriana Aparecida Dragone Silveira (UFPR), Maria Auxiliadora Monteiro Oliveira (PUC-MG), Mônica Herman Salém Caggiano (USP e Mackenzie) e Rosana Maria Gemaque Rolim (UFC); Marcos Bassi foi responsável por 1 orientação (UFSC) e por 1 co-orientação (UFPR); 89 outros docentes orientaram 1 único trabalho cada um; em 2 trabalhos não foi possível identificar os orientadores.

As palavras-chave mais encontradas foram: Políticas Públicas e Políticas Públicas de Educação, em 28 trabalhos; Direito à Educação, Educação e Direito, Direitos Sociais e Direitos Humanos em 22; Financiamento da educação, Financiamento da Educação Básica, História do Financiamento da Educação em 16; Custo Aluno Qualidade em 10; EJA PROEJA e PMEA em 9; Creche, Educação Infantil, Brasil Carinhoso em 8; Plano Nacional de Educação em 5; Remuneração Docente e Trabalho Docente em 4; com o mesmo número foram registradas Qualidade do Ensino, Qualidade da Educação; com 3 citações foram registrados o FUNDEF, Federalismo e Regime de Colaboração, Ensino Médio Escola de Tempo Integral, e Ensino Superior, Neoliberalismo, Reforma Neoliberal e Parceria Público-Privado; com 2 citações foram encontrados os termos Avaliação Escolar, Educação Básica, Fundos Contábeis, Ensino Municipal, FUNDEB e Migrações; 50 outros termos foram empregados uma única vez. A grande variedade de palavras-chave pode dificultar a localização do texto por parte de consulentes.

A metodologia e/ou os procedimentos metodológicos foram explicitados nos resumos de 68 produções $(60,18 \%)$, por outro lado, em $45(39,82 \%)$ não foram registradas quaisquer 
menções. O materialismo histórico dialético foi indicado em 4 trabalhos, a abordagem histórico-crítica, a etnografia e a teoria de ação social em 1 cada; termos mais vagos como abordagem qualitativa e abordagem quali-quantitativa, ambos com 2 citações, estiveram presentes. Os procedimentos metodológicos mencionados foram: análise documental (51 vezes); entrevistas (31); estudo de caso, estudo de casos múltiplos (8); estudo comparado (7); observação (3); pesquisa participante e pesquisa-ação (2); análise do conteúdo, análise do discurso, grupo focal e participação em debates (1).

Nos resumos de 24 produções, correspondente a 21,24\% do total, sendo 10 de doutorado e 14 de mestrado, foram feitas referências a autores. O exame de cada tipo de produção revelou que nas teses essa referência equivale a $38,48 \%$ dos trabalhos, nas dissertações acadêmicas a $18,67 \%$ e, nas produções de mestrado profissional, a 44,44\%. Observou-se que há uma tendência maior de citação nas produções mais recentes. O número de autores citados variou de 1 autor em 5 trabalhos a 10 autores em 2 produções, outros citaram maior número, registrando-se produções com 11, 14, 19 e 23 autores. O referencial ajuda o leitor a situar-se, porém um número elevado de citações pode causar efeito contrário em um texto conciso como deve ser o resumo.

Dentre os elementos que o resumo deve conter, a apresentação dos resultados ou conclusões da pesquisa é fundamental para a compreensão do trabalho. Das 83 produções completas analisadas, verificou-se que apenas 2 resumos não apresentaram esse quesito. É de se registrar como positiva essa incorporação ao texto, bem como mencionar sua afirmação, uma vez que nos últimos 3 anos todas as teses e dissertações observaram tal exigência.

As subtemáticas abordadas foram classificadas em 11 categorias, considerando o assunto tratado a partir da análise das produções. As subcategorias não são mutuamente excludentes, uma vez que há produções que abrangem mais de um assunto. A classificação, considerando essas condições, deu-se a partir do que, a nosso ver, mostrou-se como assunto predominante. O resultado da classificação encontra-se na Tabela 1.

Tabela 1 - Número e percentual de subtemas, conforme nível de formação

\begin{tabular}{l|c|c|c|c|c}
\hline Subtemas & Número & \% & DO & MA & MP \\
\hline Níveis, Etapas e Modalidades de Ensino & 33 & 29,21 & 5 & 24 & 4 \\
\hline Políticas e Programas Educacionais & 23 & 20,35 & 5 & 15 & 3 \\
\hline Fundos Públicos & 14 & 12,39 & 3 & 10 & 1 \\
\hline Estudos Comparados & 10 & 8,85 & 7 & 3 & - \\
\hline Direitos Humanos e Direitos Sociais & 8 & 7,08 & 2 & 6 & - \\
\hline Teorias e Conceitos & 7 & 6,19 & 4 & 3 & - \\
\hline Controles Públicos Externos & 6 & 5,31 & - & 6 & - \\
\hline Magistério & 4 & 3,54 & 2 & 2 & - \\
\hline Planos Nacionais de Educação & 4 & 3,54 & 1 & 2 & 1 \\
\hline Federalismo, Regime de Colaboração, e Parcerias & 4 & 3,54 & - & 4 & - \\
\hline Total & $\mathbf{1 1 3}$ & $\mathbf{1 0 0 , 0 0}$ & $\mathbf{2 9}$ & $\mathbf{7 5}$ & $\mathbf{9}$ \\
\hline
\end{tabular}

Legenda: DO - Tese de Doutorado; MA - Dissertação de Mestrado Acadêmico; MP - Dissertação de Mestrado Profissional. Fonte: Elaboração do Autor. 
O Direito à Educação no Brasil e seu Financiamento

A categoria com maior frequência foi denominada Níveis, Etapas e Modalidades de Ensino, considerando o disposto no Art. 10 da Lei 11494/2007 que regulamentou o FUNDEB e na denominação do Capítulo I da Lei 9394/96. As produções classificadas nessa categoria abordaram os seguintes assuntos: educação infantil, ensino fundamental, ensino médio, ensino superior, educação especial, educação no campo, educação quilombola, educação hospitalar e educação indígena. Estão nessa categoria 33 produções, sendo 24 de mestrado acadêmico, 5 de doutorado e 4 de mestrado profissional.

O ensino básico, com ênfase no fundamental, foi o mais encontrado, a seguir a educação infantil e, com menor incidência, o ensino médio e o superior. A ênfase ao primeiro pode ser explicada pelas demandas sociais, representadas por movimentos e campanhas ao longo do período, bem como pelas alterações constitucionais, dentre estas a ampliação da obrigatoriedade da educação dos 4 aos 17 anos (Art. 208, I da Constituição Federal) e as edições do FUNDEF e, posteriormente, do Fundo de Manutenção e Desenvolvimento do Ensino Básico e de Valorização dos Profissionais da Educação (FUNDEB) (Art. 60 do Ato das Disposições Constitucionais Transitórias, Emendas Constitucionais 14/96 e 53/06).

O número de matrículas do ensino fundamental registrou um decréscimo de 1,42\% no período de 2009-2018, de acordo com o INEP (BRASIL, 2020). A situação pode ser explicada, dentre outros possíveis motivos, pela diminuição da dinâmica populacional, pela diminuição nos bolsões dos que estavam fora da escola, assim como pela regularização do fluxo escolar. A cobertura praticamente completa do ensino fundamental, com sua duração em anos e dias ampliados, o reconhecimento de sua imprescindibilidade por parte da população e a política de fundos contribuiu, muito provavelmente, para a problematização de sua oferta, desenvolvimento e manutenção, dessa forma se explica o número de produções sobre tal etapa.

Produções sobre a educação infantil vieram a seguir. Velloso (2001) assim como Jacomini e Cruz (2019) ressaltaram a necessidade de maior número de pesquisas sobre essa etapa da educação, como resultado do período em que analisaram produções, ou seja 2000 a 2010. Os trabalhos sobre a educação infantil, considerando uma análise transversal dos subtemas, revelaram um crescimento considerável nos últimos tempos e ocuparam lugar de destaque entre as demais etapas. O crescimento é de 29,31\% no decênio 2009-2018, conforme dados do INEP (BRASIL, 2020), explicado pela pressão da população por vagas, pela importância dada ao desenvolvimento nessa faixa etária e pelo financiamento, dentre outras razões. O crescimento pode ser considerado, além de outros possíveis motivos, como indutor às produções sobre essa etapa.

A seguir veio a Educação de Jovens e Adultos com 5 produções. Jacomini e Cruz (2019) levantaram a importância de pesquisas sobre esta modalidade de ensino; Pinto (2018) igualmente reconheceu a importância e criticou o valor disponível por aluno tanto na EJA quanto na creche e no ensino médio. Em continuidade, verificou-se a produção sobre Educação Especial com 3 trabalhos, a Educação Hospitalar com 2 e a Educação Indígena e a Quilombola com 1 pesquisa cada; estas subcategorias foram pouco representadas no período. Além desta classificação específica, níveis e etapas foram também analisados como temas transversais em outras subcategorias.

O ensino médio acadêmico registrou uma diminuição de $7,52 \%$ no número de matrículas no decênio, conforme dados do INEP (BRASIL, 2020), e a educação profissional, ao contrário, 
registrou para o mesmo período e na mesma fonte um crescimento de 121,01\%. Essa etapa é gratuita e obrigatória constitucionalmente até os 17 anos. Apesar de sua importância para o desenvolvimento pessoal, para o exercício da cidadania e qualificação para o trabalho, conforme o Art. 205 da Constituição Federal, essa etapa registrou poucos trabalhos.

No mesmo período, o ensino superior registrou um crescimento de $40,35 \%$, conforme dados do INEP (BRASIL, 2020), sendo a maior parte das matrículas no ensino particular com fins lucrativos; houve ainda um crescimento no ensino a distância. Apesar desses números, foram poucos os estudos sobre esse nível de ensino. Apesar de não ser considerado como obrigatório, o ensino superior público exige mais estudos na perspectiva de ampliação dos direitos, tal como abordado por Dourado (2019).

Políticas e Programas. Educacionais foi a segunda categoria selecionada com produções sobre as instâncias: municipal, estadual, distrital e federal. Foram analisadas as situações de 10 municípios brasileiros, situados em diferentes regiões do País, sendo estudada a respectiva rede/sistema de ensino ou segmento em determinados períodos; foram analisados os impactos de programas federais e estaduais em 7 estados brasileiros e outros 6 programas federais foram analisados considerando o país todo. Essa categoria compreendeu 23 produções, sendo 15 de mestrado acadêmico, 5 de doutorado e 3 de mestrado profissional.

A discussão e produção sobre política educacional e financiamento sofreu grande ampliação e importância no período em estudo. A ANPAE, para exemplificar, fundada em 1961 como Associação Nacional de Professores de Administração Educacional, alterou sua denominação ao substituir a expressão Professores por Profissionais em 1971, registrou nova alteração ao trocar a expressão Escolar por Educacional em 1980 e finalmente passou a denominar-se Associação Nacional de Política e Administração da Educação a partir de 1996. Santos (2013), ao analisar publicações sobre financiamento da educação, constatou que a Revista Brasileira de Política e Administração da ANPAE foi o veículo com maior número de publicações no período de 1996 a 2010.

Outro exemplo é encontrado na Associação Nacional de Pós-Graduação e Pesquisa em Educação (ANPED), cuja publicação, Revista Brasileira de Educação, foi analisada por Vieira e Sousa (2012) no período de 2007 a 2011. Segundo os autores, a análise revelou "a consolidação de temas e áreas consagradas", dentre estas "Estado e políticas educacionais", destacaram também "[...] a ênfase na discussão sobre as políticas públicas como uma característica forte no campo educacional" (VIEIRA; SOUSA, 2012, p. 476).

Em terceiro lugar estiveram os trabalhos sobre Fundos Públicos. Nessa categoria se situam 4 trabalhos sobre uma análise geral da política de fundos para a educação e custo aluno, 2 trabalhos exclusivamente sobre o FUNDEF, 6 sobre o FUNDEB e 2 outros envolvendo estes fundos. Essas pesquisas foram desenvolvidas em 14 trabalhos, sendo 10 de mestrado acadêmico, 3 de doutorado e 1 de mestrado profissional.

Em relação a essa categoria, na análise feita sobre o período de 1988 a 2004, Gomes, Carnielli, Jesus e Leal (2007) constataram que os principais temas abordados foram: vinculação de recursos orçamentários para a educação, FUNDEF, legislação específica, escassez de recursos e problemas na administração dos mesmos; Jacomini e Cruz (2019), que analisaram teses e dissertações sobre financiamento da educação, defendidas no período de 2000 a 2010 , chegaram a conclusões semelhantes. 
Pinto (2018), ao analisar o financiamento da educação brasileira, constatou a ampliação de recursos decorrentes desses fundos; por outro lado, ressaltou o baixo valor disponível por aluno, principalmente em relação ao ensino médio e Educação de Jovens e Adultos e a necessidade da observação do custo aluno qualidade inicial (CAQi) em todas as etapas. Tanto o FUNDEF quanto o FUNDEB foram indutores à municipalização do ensino no País, em especial do ensino fundamental. Um dos pontos nevrálgicos envolvidos nas discussões sobre os fundos é a já citada questão do custo aluno qualidade, assunto esse que merece análise aprofundada tendo em vista ser uma das condições essenciais para o ensino de qualidade; Velloso (2001) já havia assinalado a necessidade de estudos sobre o assunto. Outro ponto importante se refere ao salário educação, que não registrou nenhuma produção sob os descritores citados; Santos (2013) já observara a necessidade de estudos sobre o tema.

A seguir se situou a categoria Estudos Comparados, na qual predominam numericamente as teses de doutorado, com 7 produções e 3 de mestrado acadêmico. Foram comparadas as situações educacionais entre 2 unidades escolares brasileiras, entre 2 municípios brasileiros em 2 trabalhos, no Mercosul em 3 pesquisas, entre o Brasil e outros países, sendo 2 da América do Sul, 1 da Espanha e 1 dos Estados Unidos, totalizando 4 trabalhos. Verificou-se que as pesquisas se concentraram em países de língua portuguesa e espanhola. Corroborou-se o estudo de Gomes (2015), que analisou 97 artigos que se valeram dos estudos comparados e constatou que a maioria se situou no eixo ibero-americano e aventou como hipótese o problema linguístico dos autores.

A categoria Direitos Humanos e Direitos Sociais congregou trabalhos sobre direito à educação, seguridade social, movimentos sociais, relação de segmentos populacionais com o mundo do trabalho e imigrações, sendo analisadas a boliviana e a haitiana. Embora referências a direitos humanos tenham sido feitas em outras categorias, enfatizamos nesta os que tratam especificamente desse quesito, daí a variedade de situações. Os trabalhos que compõem essa categoria provêm de 6 mestrados acadêmicos e 2 doutorados; destas produções, 4 são da área de educação, 1 é de saúde e 3 de direito. A propósito dessa temática, Dourado (2019) analisou a situação do país, reconheceu os avanços da Constituição Federal de 1988 assim como a necessidade de materializar e ampliar os direitos sociais na procura de superação dos limites da modernização conservadora e excludente.

Em sexto lugar, foi registrada a categoria Teorias e Conceitos, abrangendo produções que analisaram teoria e princípios jurídicos aplicados à educação, análise de dispositivos legais, questões referentes à qualidade do ensino e proposta de programa na área do transporte escolar. Essa categoria é composta por 7 produções, sendo a única com maior número de trabalhos no doutorado, com 4 pesquisas, e 3 no mestrado acadêmico; outra peculiaridade é que 2 produções foram realizadas em Programas de Pós-graduação em Educação, 1 em Transporte e 4 em Direito. A pouca incidência de estudos dessa categoria na área educacional foi também constatada por Martins e Silva (2011) na análise que fizeram sobre teses e dissertações apresentadas no período de 2000 a 2008.

Controles Públicos Externos foi a categoria seguinte com pesquisas sobre a atuação e percepção do trabalho do Ministério Público em relação à educação, judicialização de direitos educacionais, sobre a atuação do Supremo Tribunal Federal na garantia de direito à educação e na atuação do Tribunal de Contas Estadual na apuração da aplicação de recursos do FUNDEF. Os 6 trabalhos desse grupo foram realizados em mestrados acadêmicos. Duarte 
(2007) ressaltou o papel essencial do Estado na efetivação dos direitos fundamentais de natureza social, dentre eles a oferta do ensino. Daí a importância do papel conferido ao Ministério Público na exigibilidade desses direitos. Os Tribunais de Conta, por sua vez, desempenham atividades de verificação do gasto público, no caso em estudo, na área educacional.

Em oitavo lugar foi registrada a categoria Magistério, reunindo trabalhos sobre jornada de trabalho docente, profissionalização dos trabalhadores de creches, valorização salarial na comparação trabalhista entre escola pública e escola particular e análise de política de formação docente. Nessa categoria foram registrados 4 trabalhos, sendo 2 de doutorado e 2 de mestrado acadêmico. A subtemática abordada se ancora no Art. 206 e seus incisos da Constituição Federal, no qual se estabelecem os princípios que devem ser observados no ensino; dentre os quais estão a "liberdade de ensinar, pesquisar e divulgar o pensamento, a arte e o saber", enfim a liberdade de cátedra, o "pluralismo de ideias", a "valorização do magistério" e o "piso salarial".

Planos Nacionais de Educação é a categoria que envolveu estudos sobre a educação infantil nas propostas pós 1990, a dinâmica participativa na elaboração do PNE 2014-2024, o gasto por aluno e os recursos financeiros requeridos pelas metas estabelecidas. Os trabalhos que estão nessa categoria são em número de 4 , sendo 2 do mestrado acadêmico, 1 do doutorado e 1 do mestrado profissional. A existência de plano nacional decenal de educação é prevista no Art. 212 da Constituição Federal, sendo elencadas suas finalidades, dentre as quais figuram "II - universalização do atendimento escolar" e "III - melhoria da qualidade do ensino". A questão do custo aluno apareceu nessa subcategoria e mais especificamente quando foram analisados os trabalhos arrolados no subgrupo Fundos Públicos.

Federalismo, Regime de Colaboração e Parcerias é a denominação do bloco que compreendeu pesquisas sobre parceria público-privada, o direito à educação no federalismo brasileiro, o regime de colaboração entre instâncias federativas e análise do trabalho entre estado e município. As 4 produções dessa categoria foram desenvolvidas em mestrado acadêmico. A temática ganha relevo ao se discutir a questão do sistema nacional de educação e a relação entre as instâncias administrativas. Diferentes experiências têm sido desenvolvidas nessa direção, nem sempre com resultados duradouros (OLIVEIRA; GANZELI, 2013).

\section{Considerações Finais}

O levantamento das dissertações e teses, que tratam do binômio direito à educação e seu financiamento, revelou uma crescente ampliação no número de trabalhos bem como uma abrangência maior nos subtemas abordados. Essa tendência mostra uma diferenciação em relação aos estudos anteriormente citados. Tal ampliação se deve, muito provavelmente, a dois fatores: ao aumento do número de cursos de Pós-graduação stricto sensu e suas exigências e à importância que a temática passou a assumir no período.

Os 113 trabalhos analisados foram provenientes de 53 instituições, sendo 81 Programas de Pós-graduação em Educação e 21 Programas de outras áreas. O crescente número de produções que consideram o binômio citado bem como o envolvimento de outras áreas de conhecimento nas abordagens revelam a dinamicidade dos programas stricto sensu, lançam luzes sobre a temática, possibilitam acúmulo de conhecimento e a socialização da produção por intermédio do Banco de Dados da CAPES. 
O Direito à Educação no Brasil e seu Financiamento

No período em tela, o estudo da política educacional e de seu financiamento esteve em pauta. Nesse sentido, ANPAE, ANPED e Associação Nacional de Pesquisa em Financiamento da Educação (FINEDUCA) tiveram um papel de destaque em suas reuniões, publicações e debates sobre a temática; outras entidades da sociedade civil também foram protagonistas desses movimentos. Políticas adotadas pelos governos, nas três instâncias, também contribuíram para as pesquisas; dentre as quais se destacam: a aprovação do Estatuto da Criança e do Adolescente (ECA), as edições dos fundos públicos, os Planos Nacionais de Educação, o piso salarial nacional docente, além de outros programas federais, estaduais e municipais.

A garantia em lei do direito à educação é um passo importante por assegurar, do ponto de vista legal, a sua existência e o reconhecimento de uma dívida do Estado para com seu cidadão. Porém a existência da lei, por si só, não garante necessariamente seu cumprimento. É necessário o seu financiamento a partir do estabelecimento da fonte de recursos, da previsão da abrangência das ações, do nível de qualidade de sua execução e dos prazos para os desembolsos. Em relação ao direito à educação e seu financiamento, a Constituição Federal assegurou a obrigatoriedade e a gratuidade, conforme a idade e nível de ensino, estabeleceu o valor aluno pela política de fundos e as regras que devem ser observadas pelas instâncias administrativas governamentais para a oferta, manutenção e desenvolvimento do ensino.

A produção analisada revelou a ampliação e a disciplina na alocação dos recursos para a educação básica, via política de fundos, principalmente na vigência do FUNDEB: a existência de redes ou sistemas municipais de educação e a previsão de seus controles sociais e governamentais; a inclusão da educação infantil e do ensino médio no FUNDEB; a consideração de diferentes etapas, modalidades e tipos de escolas nas ponderações para a distribuição de recursos por aluno. Apesar do reconhecimento de avanços, as produções revelaram a escassez de recursos para a garantia do direito com qualidade. As análises de planos e programas revelaram o alcance das propostas, pontos fortes e fracos e a prevalência de políticas de governo sobre as de Estado.

A análise revelou também a necessidade de os estudos comparados não ficarem adstritos aos países lusofônicos e ibero-americanos; os estudos ganham com uma abertura maior e domínio linguístico mais amplo. A subtemática Teorias e Conceitos necessita ser aprofundada nos Programas de Pós-graduação em Educação, uma vez que, dos 7 trabalhos registrados, 5 foram desenvolvidos em programas de outras áreas; o desenvolvimento de trabalho conjunto entre programas de áreas que se complementam pode contribuir para o avanço do conhecimento.

Considerando os novos tempos, desafios se fazem presentes nas pesquisas de PósGraduação em teses e dissertações que tratem do binômio direito à educação e financiamento: a cobertura da educação gratuita e obrigatória; a situação do ensino médio, do ensino profissionalizante e dos cursos superiores; o ensino integral de tempo integral; o novo FUNDEB, sua regulamentação; a regulamentação do CAQ; o ensino híbrido e o ensino a distância; a situação do magistério; a questão do sistema nacional de educação, das relações federativas, das parcerias público-privado e das privatizações. Enfim, cabem estudos que visam a assegurar e alargar os direitos sociais, dentre estes o direito à educação e o seu financiamento, condição fundamental para sua materialização. 
O Direito à Educação no Brasil e seu Financiamento

\section{Referências}

BRASIL. Constituição da República Federativa do Brasil. Diário Oficial da União, Brasília, 1988. Disponível em: http://www.planalto.gov.br/ccivil_03/Constituicao/Constituicao.htm. Acesso em: 6 jul. 2020.

BRASIL. Lei no 9394, de 20 de dezembro de 1996. Lei de Diretrizes e Bases da Educação Nacional. Diário Oficial da União, Brasília, 1996. Disponível em: https://www.planalto.gov.br/ ccivil_03/Leis/L9394.htm. Acesso em: 6 jul. 2020.

BRASIL. Lei $n^{\circ}$ 11494, de 20 de junho de 2007, que regulamenta o FUNDEB. Diário Oficial da União, Brasília, 2007. Disponível em: http://www.planalto.gov.br/ccivil_03/_Ato20072010/2007/Lei/L11494.htm. Acesso em: 6 jul. 2020.

BRASIL. Ministério da Educação. Instituto Nacional de Estudos e Pesquisas Educacionais Anísio Teixeira. (site). Brasília, 2020. Disponível em: https://www.gov.br/inep/pt-br. Acesso em: 8 jul. 2020.

CURY, Carlos R. J. A Qualidade da Educação Brasileira como direito. Educação \& Sociedade, Campinas, v. 35, n. 129, p. 1053-1066, out./dez. 2014.

CURY, Carlos R. J. Financiamento da Educação Brasileira: do subsídio literário ao FUNDEB. Educação \& Realidade, Porto Alegre, v. 43, n. 4, p. 1217-1252, dez. 2018.

DAVIES, Nicholas. Levantamento Bibliográfico sobre Financiamento da Educação no Brasil. Educação em Revista, Marília, v. 15, n. 1, p. 91-162, jan./jun. 2014.

DOURADO, Luiz Fernandes. Estado, educação e democracia no Brasil: retrocessos e resistências. Educação \& Sociedade, Campinas, v. 40, e0224639, 2019.

DUARTE, Clarice Seixas. A educação como um direito fundamental de natureza social. Educação \& Sociedade, Campinas, v. 28, n. 100, p. 691-713, out. 2007.

FERREIRA, Norma Sandra Almeida. As pesquisas denominadas "estado da arte". Educação \& Sociedade, Campinas, v. 23, n. 79, p. 257-272, ago. 2002.

GOMES, Cândido Alberto. Educação Comparada no Brasil: esboço de agenda. Revista Brasileira de Estudos Pedagógicos, Brasília, v. 96, n. 243, p. 243-258, maio/ago. 2015.

GOMES, Cândido Alberto; CARNIELLI, Beatrice Laura; JESUS, Wellington Ferreira de; LEAL, Helder Bueno. O financiamento da educação brasileira: uma revisão da literatura. Revista Brasileira de Política e Administração da Educação, Porto Alegre, v. 23, n. 1, p. 29-52, jan./abr. 2007.

JACOMINI, Márcia Aparecida; CRUZ, Rosana Evangelista. O financiamento da educação na produção acadêmica de programas de pós-graduação no Brasil (2000-2010). Revista de Educação Pública, Cuiabá, v. 28, n. 69, p. 653-675, set./dez. 2019

MACHADO, Lourdes Marcelino; OLIVEIRA, Romualdo Portela de. Direito à Educação e Legislação do Ensino. In: WITTMANN, Lauro Carlos; GRACINDO, Regina Vinhaes (Coord.). O Estado da Arte em Política e Gestão da Educação no Brasil - 1991 a 1997. Brasília: ANPAE, Campinas: Editora Autores Associados, 2001. 
MARTINS, Ângela Maria; SILVA, Vandré Gomes da. O estado da arte sobre gestão, autonomia escolar e órgãos colegiados: uma visão geral. In: MARTINS, Ângela Maria et al. (Org.). Estado da arte: gestão, autonomia escolar e órgãos colegiados (2000-2008). Brasília: Liber Livros, 2011.

OLIVEIRA, Cleiton de; GANZELI, Pedro. Relações intergovernamentais na educação: fundos, convênios, consórcios públicos e arranjos de desenvolvimento da educação. Educação \& Sociedade, Campinas, v. 34, n. 125, p. 1031-1047, out./dez. 2013.

OLIVEIRA, Cleiton de; SILVA, Guaracy. O Novo Regime Fiscal: tramitação e impactos para a Educação. Revista Brasileira de Política e Administração da Educação, Goiânia, v. 34, n. 1, p. 253-269, jan./abr. 2018.

PINTO, José Marcelino de Rezende. O financiamento da educação na Constituição federal de 1988: 30 anos de mobilização social. Educação \& Sociedade, Campinas, v. 39, n. 145, p. 846-869, out./dez. 2018.

ROMANOWSKI, Joana Paulin; ENS, Romilda Teodora. As pesquisas denominadas do tipo "Estado da Arte" em Educação. Diálogo Educacional, Curitiba, v. 6, n. 19, p. 37-50, set./dez. 2006.

SANTOS, Alfredo Sérgio Ribas. O financiamento da educação no Brasil: o estado da arte e a constituição do campo (1996-2010). 2013. Disponível em: https://anpae.org.br/simposio2 6/1comunicacoes/AlfredoSergioRibasdosSantos-ComunicacaoOral-int.pdf. Acesso em: 03 jul. 2020.

STREMEL, Silvana; TELLO, Cesar; MAINARDES, Jefferson. Levantamento bibliográfico sobre estudos teóricos e epistemológicos da política educacional. ReLePe - Red Latino Americana de estudios epistemológicos em Política Educativa, Biblioteca temática. Eixo 1, 2014. Disponível em: http://relepe.org/index.php/biblioteca-tematica/87-bibliotecatematica/problematicas-y-limitaciones-en-el-desarrollo-investigativo-en-politica-educativa. Acesso em: 16 out. 2020.

VELLOSO, Jacques. Pesquisas no país sobre financiamento da educação: onde estamos?. In: WITTMANN, Lauro Carlos; GRACINDO, Regina Vinhaes (Coord.). O Estado da Arte em Política e Gestão da Educação no Brasil - 1991 a 1997. Brasília: ANPAE; Campinas: Editora Autores Associados, 2001.

VIEIRA, Carlos Eduardo; SOUSA, Sandra Záquia. A Revista Brasileira de Educação e a difusão da pesquisa educacional (2007-2011). Revista Brasileira de Educação, Rio de Janeiro, v. 17, n. 50, p. 463-482, maio/ago. 2012.

VOSGERAU, Dilmeire Sant'Anna; ROMANOWSKI, Joana Paulin. Estudos de revisão, implicações conceituais e metodológicas. Diálogo Educacional, Curitiba, v. 14, n. 14, p. 165189, jan./abr. 2014.

WITTMANN, Lauro Carlos; GRACINDO, Regina Vinhaes (Coord.). O Estado da Arte em Política e Gestão da Educação no Brasil - 1991 a 1997. Brasília: ANPAE; Campinas: Editora Autores Associados, 2001. 
O Direito à Educação no Brasil e seu Financiamento

\section{Apêndice}

Relação das 113 teses e dissertações analisadas no artigo contendo "direito a educação e financiamento" dentre as palavras chave, defendidas no período $1988-2018$.

ANDRADE, Nhayana de Freitas. Manoel Bomfim e o Pedagogium: pela defesa da nacionalização do ensino primário na Primeira República. 2014. 174 f. Dissertação (Mestrado em Educação) - Pontifícia Universidade Católica de Minas Gerais, Belo Horizonte, 2014.

ARENHARDT, Dircelei. A educação de jovens e adultos na $1^{\text {a }}$ FERED/SC - Unidade de Atendimento de Itapiranga de SC: uma análise do perfil dos alunos. 2018, 169 f. Dissertação (Mestrado em Educação) - Universidade Regional Integrada do Alto Uruguai e das Missões, Frederico Westphalen, 2018.

ARON, Aroni Allan. 0 ensino superior como atividade empresarial e o cidadão mínimo no Brasil: o peso da mão liberal e a marca de uma aliança não visível. Uma análise do ensino superior brasileiro a partir dos dilemas que envolvem as políticas públicas. 2008. $215 \mathrm{f}$. Dissertação (Mestrado em Educação) - Universidade de São Paulo, São Paulo, 2008.

BAPTISTA, Talita Seiscento. 0 direito a educação no constitucionalismo brasileiro. $O$ tratamento do direito a educação no sistema de repartição de competência acolhido pela federação brasileira. 2014. 114 f. Dissertação (Mestrado em Educação) - Universidade Presbiteriana Mackenzie, São Paulo, 2014.

BARBOSA, Luciane Muniz Ribeiro. Igreja, estado e educação em Martinho Lutero: uma análise das origens do direito à educação. 2007. 246 f. Dissertação (Mestrado em Educação) - Universidade de São Paulo, São Paulo, 2007.

BESERRA, Ana Carolina Mantovani. Políticas públicas de avaliação e direito à educação de Qualidade no Brasil. 2017. 108 f. Dissertação (Mestrado em Direito Político e Econômico) - Universidade Presbiteriana Mackenzie, São Paulo, 2017.

BORGES, Irlanda Aglaê Correia Lima. A gestão do financiamento público em escola de educação de jovens e adultos: um estudo no Distrito Federal. 2014. 127 f. Dissertação (Mestrado em Educação) - Universidade Católica de Brasília, Brasília, 2014.

BRASIL, José Huélito Maia. A seguridade social como instrumento na efetivação de direitos fundamentais. 2010. 158 f. Dissertação (Mestrado em Direito) - Universidade Federal do Ceará, Fortaleza, 2010.

BREGUNCI, Thiago Henrique Baruch. A política de financiamento e gasto público na educação brasileira. 2009. 229 f. Dissertação (Mestrado em Direito) - Pontifícia Universidade Católica de Minas Gerais, Belo Horizonte, 2009.

BRUSCATTO, Andrea Cristiane Maraschin. Políticas Educacionais para crianças de zero a cinco anos na Argentina, Brasil e Uruguai (2001-2014): um estudo comparativo. 2017. 222 f. Tese (Doutorado em Educação) - Universidade Federal do Rio Grande do Sul, Porto Alegre, 2017.

CALIXTO, Josenir de Araújo. Sistema público de educação e o regime de colaboração: uma experiência do estado do Acre e do município de Rio Branco no período de 2005 a 2012. 
2017. 170 f. Dissertação (Mestrado em Educação) - Universidade Federal do Acre, Rio Branco, 2017.

CANTUÁRIO, Valquira Macêdo. O processo de implementação da escola pública de tempo integral no Piauí. 2017. 169 f. Dissertação (Mestrado em Educação) - Universidade Federal do Piauí, Teresina, 2017.

CARBONESI, Maria Anastácia Ribeiro. A percepção de alunos e professores do ensino médio sobre a atuação do Ministério Público na defesa do direito à educação. 2008. 153

f. Dissertação (Mestrado em Educação) - Universidade Católica de Brasília, Brasília, 2008.

CARDOSO, Caroline Cristiano. Direito a educação de jovens e adultos na tessitura das políticas públicas de financiamento. 2018. 118 f. Dissertação (Mestrado em Educação) Universidade Federal do Rio Grande do Sul, Porto Alegre, 2018.

CARMO, Eraldo Souza do. A nucleação das escolas do campo no município de Curralinho - Arquipélago do Marajó: limites, contradições e possibilidades na garantia do direito à educação. 2016. 275 f. Tese (Doutorado em Educação) - Universidade Federal do Pará, Belém, 2016.

CARVALHO, Willer Luciano. Metodologia de análise para localização de escolas em áreas rurais. 2011. 223 f. Tese (Doutorado em Transportes) - Universidade Nacional de Brasília, Brasília, 2011.

CASTANHO, William Glauber Teodoro. Direitos humanos LGBTS e mundo do trabalho: tensões e convergências. 2017. 199 f. Tese (Doutorado em Direito) - Universidade de São Paulo, São Paulo, 2017.

COELHO, Maria do Carmo Irochi. Fundamentos Constitucionais do Ensino Fundamental Público - O FUNDEF - Limites jurídicos e perspectivas para o atendimento ao direito à educação. 2002. Dissertação (Mestrado em Direito) - Universidade de Ribeirão Preto, Ribeirão Preto, 2002*.

COSTA Elisângela André da Silva. A educação de jovens e adultos e o direito à educação: concepções e olhares de educador es e gestores escolares a partir das políticas educacionais do município de Horizonte/ Ceará. 2014. 203 f. Tese (Doutorado em Educação) Universidade do Ceará, Fortaleza, 2014.

COSTA, Kelly Patrícia Carneiro da. O Contexto ribeirinho: crianças e adultos da Barra de São Lourenço e suas práticas educativas (Corumbá, MS). 2013. 85 f. Dissertação (Mestrado em Educação) - Universidade Federal de Mato Grosso do Sul, Corumbá, 2013.

COSTA, Nathália Dourado Frazão. Educar a infância? Problematizando práticas de Educação Infantil no Brasil em relatórios do UNICEF, de 1990 a 2014. 2015. 88 f. Dissertação (Mestrado em Psicologia Social) - Universidade Federal do Pará, Belém, 2015.

COUTO, Maria Aparecida Freire de Oliveira. Do "limbo ao direito": a distribuição dos recursos financeiros para as creches utilizando o referencial do custo aluno - qualidade inicial - CAQi. 2012. 133 f. Dissertação (Mestrado em Educação) - Universidade Federal de Pernambuco, Recife, 2012. 
DANTAS, Éder da Silva. Do FUNDEF ao FUNDEB: consensos e dissensos em torno da universalização da educação básica. 2010. Tese (Doutorado em Educação) - Universidade Federal da Paraíba, João Pessoa, 2010*.

DUBBERSTEIN, Flávia Costa Lima. Implicações da dinâmica do financiamento da educação para as desigualdades intermunicipais quanto ao gasto por aluno no Espírito Santo. 2015. 103 f. Dissertação (Mestrado em Educação) - Universidade Federal do Espírito Santo, Vitória, 2015.

EVANGELISTA, Alessandra Reis. A EJA no contexto da política de fundos contábeis: o caso de Juiz de Fora. 2013. 123 f. Dissertação (Mestrado em Educação) - Universidade Federal do Rio de Janeiro, Rio de Janeiro, 2013.

FARIAS, Emerson de Souza. Atuação do Ministério Público Estadual na defesa do direito à educação de crianças e adolescentes no Piauí. 2018. 203 f. Dissertação (Mestrado em Educação) - Universidade Federal do Piauí, Teresina, 2018.

FERNANDES, Eliane. Financiamento da educação infantil no Brasil: descrição e análise da participação do governo federal no período de 2000 a 2016. 2018. 251 f. Dissertação (Mestrado em Educação) - Universidade Estadual de Campinas, Campinas, 2018.

FERNANDES, Valquíria Pinheiro Silva. O conhecimento sobre financiamento da educação - FUNDEM: o que dizem as docentes da educação infantil. 2017. 190 f. Dissertação (Mestrado em Educação) - Universidade Estadual de Santa Cruz, Ilhéus, 2017.

FERREIRA, Eveline Andrade. Políticas de Formação de professores pós-LDB: o Programa MAGISTER/CEARÁ na visão de seus gestores. 2004. 188 f. Dissertação (Mestrado em Educação) - Pontifícia Universidade Católica de Minas Gerais, Belo Horizonte, 2004.

FONSECA, Márcia Mascarenhas da. Políticas para o Ensino Superior de Turismo: um estudo numa instituição de Belo Horizonte. 2005. Dissertação (Mestrado em Educação) Pontifícia Universidade Católica de Minas Gerais, Belo Horizonte, 2005*.

FONTELES, Izabelle Marques. Financiamento educacional e a gestão financeira descentralizada: uma análise do Programa Municipal de Manutenção e Desenvolvimento do Ensino de Fortaleza. 2018. 107 f. Dissertação (Mestrado em Educação) - Universidade Estadual do Ceará, Limoeiro do Norte, 2018.

FRANÇA, Marileide Gonçalves. Financiamento da Educação Especial: complexas tramas, permanentes contradições e novos desafios. 2014. 365 f. Tese (Doutorado em Educação) Universidade de São Paulo, São Paulo, 2014.

FREITAS, Aline da Silva. 0 direito à educação básica no Brasil e o problema de seu financiamento. 2009. 185 f. Dissertação (Mestrado em Direito) - Universidade Presbiteriana Mackenzie, São Paulo, 2009.

FROIS, Maria Thereza Antunes Fortes de Menezes. Sistema educacional inclusivo: uma garantia de acesso para alunos com necessidades especiais no ensino médio em Barbacena? 2017. 130 f. Dissertação (Mestrado em Educação) - Universidade Federal de Juiz de Fora, Juiz de Fora, 2017. 
FURTADO, Patrycia Byanca. O FUNDEF e o Tribunal de Contas do Estado de Santa Catarina: ruptura e intersecções. 2010. 300 f. Dissertação (Mestrado em Educação) Universidade Federal de Santa Catarina, Florianópolis, 2010.

GOBETE, Girlene. Política Educacional no Município de Vitória no período de 1989 a 2004: implicações nas políticas de Educação Especial. 2005. Dissertação (Mestrado em Educação) - Universidade Federal do Espírito Santo, Vitória, 2005*.

GOMES, Fernando Alves. Aplicação da teoria social sistêmica no desenho normativo das políticas públicas; o caso do Sistema Nacional de Educação. 2017. Tese (Doutorado em Direito) - Universidade de São Paulo, São Paulo, 2017*.

GOMES, Lucas Alves de Oliveira. A efetividade do direito constitucional à educação infantil a partir dos recursos financeiros oriundos do FUNDEB no município de Salvador/ Bahia nos anos de 2013 a 2016. 2017. 101 f. Dissertação (Mestrado em Políticas Sociais e Cidadania) - Universidade Católica do Salvador, Salvador, 2017.

GONÇALVES, Adriano de Freitas. A evolução histórica do financiamento educacional brasileiro e a importância do FUNDEF/FUNDEB para a educação básica de Mairiporã. 2013. 83 f. Dissertação (Mestrado em Educação) - Universidade Cidade de São Paulo, São Paulo, 2013.

GOUVEIA, Andreia Barbosa, Partidos Políticos e trajetórias das políticas educacional municipal: um estudo sobre a administração do PFL em Curitiba e do PT em Londrina. 2008. 286 f. Tese (Doutorado em Educação) - Universidade de São Paulo, São Paulo, 2008.

HOCHULI, Elisângela Belniaki. A política do transporte escolar e a garantia do direito à educação à luz do regime de colaboração: o exemplo do Paraná. 2014. 219 f. Dissertação (Mestrado em Educação) - Universidade Federal do Paraná, Curitiba, 2014.

JESUS, Wellington Ferreira de. A política de fundos constitucionais no contexto da educação básica no Brasil: origens, contradições e perspectivas. 2011. 268 f. Tese (Doutorado em Educação) - Universidade Federal de Goiás, Goiânia, 2011.

LIMA, Bruna Mota de. $O$ investimento público em educação pública para o alcance das metas previstas no Plano Nacional de Educação (PNE) 2014-2024. 2018. $101 \mathrm{f}$. Dissertação (Mestrado em Políticas Públicas e Desenvolvimento) - Instituto de Pesquisa Econômica Aplicada - IPEA, Brasília, 2018.

LIMA, Ubirajara Couto. As práticas de participação institucionalizadas e sua relação com a cultura política: um estudo sobre o Conselho de Acompanhamento e Controle Social do FUNDEB. 2009. 66 f. Dissertação (Mestrado em Educação) - Universidade Federal da Bahia, Salvador, 2009.

LIMEIRA, Luciana Cordeiro. Direito à educação básica no Distrito Federal: a complexa relação entre sua compreensão e a atuação de diferentes atores sociais. 2018. 317 f. Tese (Doutorado em Educação) - Universidade Católica de Brasília, Brasília, 2018.

LOPES, Elisângela Pereira. Modelo de gestão para o transporte escolar rural nos estados e municípios brasileiros. 2009. 190 f. Dissertação (Mestrado em Transportes) Universidade Nacional de Brasília, Brasília, 2009. 
LOURENÇO, Valéria Jabur Maluf Mavuchian. Direito, educação e sustentabilidade: a complementariedade entre ensino superior jurídico público e privado. 2017. 117 f. Dissertação (Mestrado em Direito) - Universidade Nove de Julho, São Paulo, 2017.

MANTOVANI, Cinthia Maria Bueno Marturelli. PROUNI: as estratégias das IES privadas frente aos seus desafios. 2013. 121 f. Dissertação (Mestrado em Educação) - Universidade do Oeste Paulista, Presidente Prudente, 2013.

MARINO, Virgínia Gonçalves de Oliveira. Educação e pessoas com deficiência - a transitoriedade entre a universalização e a focalização. 2017. 136 f. Dissertação (Mestrado em Educação) - Universidade de São Paulo, São Paulo, 2017.

MATEUS, Douglas Predo. A efetividade do direito à educação no Brasil e Mercosul. O Tratado de Assunção e a educação. 2008. 88 f. Dissertação (Mestrado em Direito Internacional) - Universidade Católica de Santos, Santos, 2008.

MATHIAS, Fabiana Soares. Um estudo comparativo das trajetórias de afirmação do direito de universalização da educação obrigatória no Brasil e Uruguai. 2009. 177 f. Dissertação (Mestrado em Educação) - Universidade Federal do Rio Grande do Sul, Porto Alegre, 2009.

MAZOTTI, Marcelo. $\mathbf{O}$ ativismo judicial no panorama do direito à educação: a intervenção do Poder Judiciário nas políticas públicas educacionais e seus efeitos práticos: estudo comparado entre o Brasil e os EUA. 2017. 252 f. Tese (Doutorado em Direito) - Universidade de São Paulo, São Paulo, 2017.

MEDEIROS, Milena Moura. $\mathbf{O}$ direito à educação e as classes hospitalares: discurso de gestores de um hospital- escola. 2018. 132 f. (Mestrado em Educação) - Universidade Federal da Paraíba, João Pessoa, 2018.

MELO, Regina Lúcia Couto de. 0 direito à educação infantil e a oferta pública em Minas Gerais para crianças de $\mathbf{0}$ a 6 anos dos povos quilombolas. 2016. $221 \mathrm{f}$. Dissertação (Mestrado em Educação) - Universidade Federal de Minas Gerais, Belo Horizonte, 2016.

MENEZES, Cinthya Vernizi Adachi de. Atendimento escolar hospitalar e domiciliar: um estudo comparado sobre as políticas educacionais do Paraná/Brasil e da Galícia/Espanha. 2018. 429 f. Tese (Doutorado em Educação) - Universidade Federal do Paraná, Curitiba, 2018.

MONTEIRO, Helena Oliveira da Cruz. O Plano Nacional de Educação 2014-2024 e o percentual do PIB como medida de financiamento da educação pública: uma avaliação crítica. 2016. 145 f. Dissertação (Mestrado em Economia) - Universidade Federal Fluminense, Niterói, 2016.

MOSNA, Rosa Maria Pinheiro. Financiamento da educação e (des)igualdade nas condições de oferta educacional: uma análise a partir de escolas da rede municipal de Porto Alegre. 2008. 245 f. Dissertação (Mestrado em Educação) - Universidade Federal do Rio Grande do Sul, Porto Alegre, 2008.

MOTTA, Thalita Cunha. Assistência estudantil e inclusão social. 2017. 317 f. Tese (Doutorado em Educação) - Universidade Federal de Pernambuco, Recife, 2017.

MOURA, João Francisco Beckman. Creche: direito fundamental da mulher e da criança na educação. 2014. 138 f. Dissertação (Mestrado em Direito) - Centro Universitário de Bauru, Bauru, 2014. 
NASCIMENTO, Ana Paula Santiago do. Avanços e retrocessos na oferta da educação infantil no Brasil: análise financeiro-orçamentária dos recursos destinados a essa etapa da educação 2001 - 2010. 2012. 228 f. Dissertação (Mestrado em Educação) - Universidade de São Paulo, São Paulo, 2012.

NASCIMENTO, Jucileide Ferreira do. As incubadoras universitárias na contrarreforma do ensino superior público no Brasil. 2017. 283 f. Tese (Doutorado em Política Social) Universidade Nacional de Brasília, Brasília, 2017.

NASCIMENTO, Maria Luzirene Oliveira do. O PRONATEC no âmbito das políticas públicas de educação profissional: da dualidade estrutural à mercantilização da qualificação profissional. 2016. 111 f. Dissertação (Mestrado em Educação) - Universidade Federal do Piauí, Teresina, 2016.

NAZARETH, Cátia Aparecida Lopes. Educação hospitalar/domiciliar no município de Juiz de Fora, Minas Gerais. 2012. 108 f. Dissertação (Mestrado em Educação) - Universidade Federal de Juiz de Fora, Juiz de Fora, 2012.

NICÁCIO, Patrícia Pereira da Silva. Análise da desigualdade das condições de oferta do ensino médio em Goiânia. 2016. 87 f. Dissertação (Mestrado em Administração) Universidade Federal de Goiás, Goiânia, 2016.

OLDRA, Alderi Antonio. Ampliação e qualificação da educação infantil no município de Erechim: relevância, desafio e limitações. 2017. 121 f. Dissertação (Mestrado em Educação) - Universidade Federal da Fronteira Sul, Erechim, 2017.

OLIVEIRA, Alberto Merchede de. Custos da Educação Infantil: O caso de duas instituições do Distrito Federal. 1998. Dissertação (Mestrado em Educação) - Universidade Católica de Brasília, Brasília, 1998*.

OLIVEIRA, Rita de Cássia. Programas PDE Escola e Mais Educação: descentralização e gestão do ensino. 2014. 355 f. Tese (Doutorado em Educação) - Universidade Federal de Juiz de Fora, Juiz de Fora, 2014.

ORÇO, Cláudio Luiz. Educação indígena: fronteiras culturais e inclusão social - análise da terra indígena Xapecó. 2008. 130 f. Dissertação (Mestrado em História) - Universidade de Passo Fundo, Passo Fundo, 2008.

PELLEGRIM, Andrea Lúcia Amorim. Educação em movimentos. Reflexões e desafios dos processos de aprendizagem em movimentos sociais de Madrid. 2016. $613 \mathrm{f}$. Tese (Doutorado em Saúde) - Universidade Federal de São Paulo, São Paulo, 2016.

PEREIRA, Soeli Terezinha. Pelo direito à creche: uma análise da ação Brasil Carinhoso e da expansão do atendimento no estado do Paraná nos anos de 2012 a 2015. 2017. $167 \mathrm{f}$. Dissertação (Mestrado em Educação) - Universidade Federal do Paraná, Curitiba, 2017.

PERIUS, Lúcia Célia Ferreira da Silva. Programa Nacional de Educação na Reforma Agrária. A gestão do PRONERA no Estado de Mato Grosso do Sul 1998/2001. 2008, 114 f. Dissertação (Mestrado em Educação) - Universidade Católica Dom Bosco, Campo Grande, 2008.

PINTO, Isabela Rahal de Rezende. A garantia do direito à educação de crianças e adolescentes pela via judicial: análise das decisões judiciais do Supremo Tribunal Federal 
O Direito à Educação no Brasil e seu Financiamento

(2003-2012). 2014. 217 f. Dissertação (Mestrado em Educação) - Universidade Federal da Grande Dourados, Dourados, 2014.

PIRES JÚNIOR, Paulo Abrão. Constituição e reconhecimento: as normas constitucionais de vinculações de recursos como garantia para a efetividade do direito a educação. 2009. 275 f. Tese (Doutorado em Educação) - Pontifícia Universidade Católica do Rio de Janeiro, Rio de Janeiro, 2009.

POPP, Bárbara. Análise das propostas de políticas públicas para o financiamento da educação infantil no município de São Paulo. 2006, 131 f. Dissertação (Mestrado em Educação) - Universidade de São Paulo, São Paulo, 2006.

POPP, Bárbara. Qualidade da Educação infantil: é possível medi-la? 2015. 169 f. Tese (Doutorado em Educação) - Universidade de São Paulo, São Paulo, 2015.

RIBEIRO, Alessandra Ferreira de Araújo. O princípio da precaução e sua aplicação pelo Poder Judiciário. 2010. 169 f. Dissertação (Mestrado em Direito) - Universidade de São Paulo, São Paulo, 2010.

RIBEIRO, Josete Maria Cangussu. A jornada de trabalho dos professores da escola pública em contexto de políticas de valorização docente e qualidade da educação. 2014 . 265 f. Tese (Doutorado em Educação) - Universidade Federal do Rio Grande do Sul, Porto Alegre, 2014.

RIBEIRO, Maria de Jesus Araújo. Impactos iniciais do FUNDEB na qualidade da educação infantil pública do município de Fortaleza. 2011. Dissertação (Mestrado em Educação) Universidade Federal do Ceará, Fortaleza, 2011*.

ROCHA, Juliana Andrade. Políticas públicas para a Educação de Jovens e Adultos em Uberlândia - MG (1990-2008). 2016. 131 f. Dissertação (Mestrado em Educação) Universidade Federal de Goiás, Catalão, 2016.

RODRIGUES, Gustavo Luís Mendes Tupinambá. 0 direito fundamental à educação: uma reflexão crítica da atividade educacional de uma comunidade de jovens e adultos no estado do Piauí. 2015. 96 f. Dissertação (Mestrado em Direito) - Pontifícia Universidade Católica do Rio Grande do Sul, 2015.

SAHB, Warlley Ferreira. Tecnologias digitais de informação e o processo de integração do ensino superior no MERCOSUL. 2016. Tese (Doutorado em Educação) - Universidade Católica de São Paulo, São Paulo, 2016*.

SANTOS, Agida Maria Cavalcante dos. O processo de desativação das Escolas Técnicas Estaduais no Amazonas. 2003. Dissertação (Mestrado em Educação) - Universidade Federal do Amazonas, Manaus, 2003.

SANTOS, Diovane Alves dos. Ressignificando a gestão através da formação e da construção do projeto político pedagógico da Secretaria de Educação. 2014. 103 f. Dissertação (Mestrado em Educação) - Universidade Federal do Pampa, Bagé, 2014

SANTOS, Waldir Jorge Ladeira dos. Financiamento e investimento da educação nos municípios de Duque de Caxias e Nova Iguaçu, R.J.: avaliação da eficácia, da efetividade 
e da transparência das políticas públicas. 2010. 300 f. Tese (Doutorado em Educação) Universidade do Estado do Rio de Janeiro, Rio de Janeiro, 2010.

SARAIVA, Emerson Sandro Silva. Políticas públicas e educação para pessoas jovens e adultas em situação de privação de liberdade no Amazonas: regulação da sociedade e antagonismos de direitos sociais. 2018. 347 f. Tese (Doutorado em Educação) - Universidade Federal do Amazonas, Manaus, 2018.

SCHLINDWEIN, Ingrid Nascimento de Aguiar. Imigração haitiana para o Brasil. Fragilidades e desafios institucionais. 2017. 177 f. Dissertação (Mestrado em Direito) - Universidade de São Paulo, 2017.

SEEMANN, Vânio Cesar. O que significa mais tempo na escola? Sobre as políticas de jornada em tempo integral nos microcontextos das redes municipais de ensino. 2016. $316 \mathrm{f}$. Dissertação (Mestrado em Educação) - Universidade do Estado de Santa Catarina, Florianópolis, 2016.

SENA, Fernanda Vick Soares de. Conferências Nacionais de Educação e as dinâmicas participativas na lei federal n¹3.005/2014. 2018. 469 f. Dissertação (Mestrado em Direito) - Universidade de São Paulo, São Paulo, 2018.

SILVA, Aliny Cristina Monteiro da. Gastos e custos do processo de implementação do ensino médio em tempo integral no Par (2012-2015). 2018. 179 f. Dissertação (Mestrado em Educação) - Universidade Federal do Pará, Belém, 2018.

SILVA, Ana Paula Silva. ¡No hablamos español! Crianças bolivianas na educação infantil paulistana. 2014. 179 f. Dissertação (Mestrado em Educação) - Universidade Federal de São Paulo, Guarulhos, 2014.

SILVA, Bruna Isabelle Simioni. O direito fundamental à educação na ordem constitucional brasileira. 2015. 146 f. Dissertação (Mestrado em Direito) - Centro Universitário Autônomo do Brasil, Curitiba, 2015.

SILVA, Fernando José Cândido da. O financiamento da educação no Brasil: o caso do município do Rio de Janeiro (2010-2016). 2018. 101 f. (Mestrado em Educação) Universidade do Estado do Rio de Janeiro, Rio de Janeiro, 2018.

SILVA, Isabel de Oliveira e. Profissionais de creche no coração da cidade: a luta pelo reconhecimento profissional em Belo Horizonte. 2004. 297 f. Tese (Doutorado em Educação) - Universidade Federal de Minas Gerais, Belo Horizonte, 2004.

SILVA, Messias Antonio da. A Escola Sagarana uma ruptura com a concepção de qualidade total anteriormente implantada na Escola Estadual Padre Eustáquio. 2002. 103 f. Dissertação (Mestrado em Educação) - Pontifícia Universidade Católica de Minas Gerais, Belo Horizonte, 2002.

SILVA, Natália Menin da. A busca por uma educação de qualidade no campo em uma escola de um assentamento de reforma agrária: a distância entre o recurso disponível e o necessário. 2013. 160 f. Dissertação (Mestrado em Educação) - Universidade de São Paulo, Ribeirão Preto, 2013. 
SILVEIRA, Adriana Aparecida Dragone. Direito à educação e o Ministério Público: uma análise da atuação de duas Promotorias de Justiça da Infância e Juventude do interior paulista. 2006. 263 f. Dissertação (Mestrado em Educação) - Universidade de São Paulo, São Paulo, 2006.

SILVEIRA, Débora Aparecida da. $O$ ensino médio e o direito à educação nas proposições do legislativo federal (1997-2014). 2016. 243 f. Dissertação (Mestrado em Educação) Universidade Federal do Paraná, Curitiba, 2016.

SILVEIRA, Dimitri Assis. O Programa DF Alfabetizado/ Brasil Alfabetizado e a continuidade dos estudos: dos números à percepção dos sujeitos. 2013. 170 f. Dissertação (Mestrado em Educação) - Universidade Nacional de Brasília, Brasília, 2013.

SOARES, Nilene Fernandes. O Projeto Escola de Tempo Integral da rede estadual do Pará na perspectiva do financiamento. 2017. 141 f. Dissertação (Mestrado em Educação) - Universidade Federal do Pará, Belém, 2017.

SOUSA, Maria do Socorro Lages de Carvalho. Avaliação do impacto do FUNDEF em Teresina/ PI: recursos e mais controle social? 2003. 96 f. Dissertação (Mestrado em Educação) - Universidade Federal do Piauí, Teresina, 2003.

SOUZA, Fernanda Cristina de. Educação infantil, educação especial e planos nacionais de educação no Brasil pós 1990. 2018. 217 f. Tese (Doutorado em Educação) Universidade de São Paulo, São Paulo, 2018.

SOUZA, Glória Maria Anselmo de. A avaliação emancipatória e gestão democrática para a construção de uma escola transformadoras no município de Niterói. 2016. 393 f. Tese (Doutorado em Educação) - Universidade Federal Fluminense, Niterói, 2016.

SOUZA, Kellcia Rezende. Direito à Educação nos países membros do MERCOSUL: um estudo comparado. 2017. 346 f. Tese (Doutorado em Educação) - Universidade Estadual paulista Júlio de Mesquita Filho, Araraquara, 2017.

TANAKA, Mariano Masayuki. Direito à previdência como direito fundamental e sua concretização no direito contemporâneo. 2015. Dissertação (Mestrado em Direito) Centro Universitário Fieo, Osasco, 2015*.

VARGAS, Gisele. Valorização salarial docente: implicações das políticas educacionais relativas à remuneração do magistério no setor privado de ensino. 2012. 81 f. Dissertação (Mestrado em Educação) - Universidade do Sul de Santa Catarina, Tubarão, 2012.

VELLOSO, Renata Mendes. O contexto das políticas públicas para infância no campo. 2008. 192 f. Dissertação (Mestrado em Educação) - Universidade Federal de Minas Gerais, Belo Horizonte, 2008.

VIEDES, Sílvia Cristiane Alfonso. Políticas públicas em alfabetização: o Pacto Nacional pela Alfabetização na Idade Certa em Anastácio, MS. 2015. 148 f. Dissertação (Mestrado em Educação) - Universidade Estadual de |Mato Grosso do Sul, Campo Grande, 2015.

VITORETTE, Jacqueline Maria Barbosa. A não consolidação do PROEJA como política pública de estado. 2014. 254 f. Tese (Doutorado em Educação) - Universidade Federal de Goiás, Goiânia, 2014. 
WAGNER, Sandra Filomena. A aplicabilidade das parcerias público-privadas na concretização da educação inclusiva no ensino fundamental. 2013. Dissertação (Mestrado em Direito Econômico e Desenvolvimento) - Universidade Cândido Mendes, 2013*.

WIITTER, Carlos Eduardo Souza Brocanella. Direito a Educação: análise jurídica e semiótica dos dispositivos constitucionais. 2005. Dissertação (Mestrado em Direito) - Centro Universitário Braz Cubas, Mogi das Cruzes, 2005*.

XIMENES, Salomão Barros. Fundo público e direito à educação: um estudo a partir dos gastos públicos da União e do Município de Fortaleza. 2006. 201 f. Dissertação (Mestrado em Educação) - Universidade Federal do Ceará, Fortaleza, 2006.

XIMENES, Salomão Barros. Padrão de qualidade do ensino: desafios institucionais e bases para a construção de uma teoria jurídica. 2014. 428 f. Tese (Doutorado em Direito) Universidade de São Paulo, São Paulo, 2014.

ZANDER, Katherine Finn. Judicialização da política de corte etário para o ingresso no ensino fundamental do Paraná. 2015. 177 f. Dissertação (Mestrado em Educação) Universidade Federal do Paraná, Curitiba, 2015.

Obs.:*Não foi indicado o número de folhas da Dissertação ou Tese porque o seu texto não está disponível.

Cleiton de Oliveira foi professor pela Universidade Estadual de Campinas (Unicamp). Formado em Pedagogia pela Unimep (Universidade Metodista de Piracicaba), mestre em Educação pela mesma instituição e doutor em Educação pela Unicamp (Universidade Estadual de Campinas). Foi docente no ensino básico, atuando em escolas de Santa Bárbara d'Oeste como "Gabriel de Oliveira", "Ulisses de Oliveira Valente" e SESI. Lecionou também no ensino superior, na Unimep, Unicamp, Unisal (Centro Universitário Salesiano de São Paulo) e Uniso (Universidade de Sorocaba). Exerceu cargos administrativos na Unimep e foi o dirigente municipal de Ensino em Santa Bárbara d'Oeste entre os anos de 1983 e 1988. Foi também conselheiro no Conselho Estadual de Educação, membro fundador da Undime, presidente do conselho da entidade, sócio e diretor para o Estado de São Paulo da ANPAE (Associação Nacional de Política e Administração de Educação), sócio da ANPED (Associação Nacional de Pós-Graduação e Pesquisa em Educação) e sócio da SBPC (Sociedade Brasileira para o Progresso da Ciência). Foi um dos responsáveis pela implantação do Museu da Imigração, em 1988, e empresta seu nome à creche do bairro Dona Regina, uma das unidades da rede municipal de Ensino de Santa Bárbara d'Oeste. Faleceu em 12 de maio de 2021.

ORCID: https://orcid.org/0000-0002-4038-0429

E-mail: cleitondeoli@gmail.com 


\section{Editores do volume 11}

Márcia Aparecida Jacomini - Universidade Federal de São Paulo, Brasil

José Marcelino de Rezende Pinto - Universidade de São Paulo, Brasil

\section{Comitê Editorial}

Nalú Farenzena - Universidade Federal do Rio Grande do Sul, Brasil

Juca Gil - Universidade Federal do Rio Grande do Sul, Brasil

Theresa Adrião - Universidade Estadual de Campinas, Brasil

Ângelo Ricardo de Souza - Universidade Federal do Paraná, Brasil

\section{Conselho Editorial}

\section{Alejandro Morduchowicz}

Universidad Pedagógica, Provincia de Buenos Aires, Argentina

Andréa Barbosa Gouveia

Universidade Federal do Paraná, Brasil

Fernanda Saforcada

Universidade de Buenos Aires, Argentina

Jacques Velloso

Universidade de Brasília, Brasil

João Monlevade

Senado Federal, Brasil

Jorge Abrahão de Castro

Instituto de Pesquisa Econômica Aplicada / IPEA, Brasil

Lisete Regina Gomes Arelaro

Universidade de São Paulo, Brasil

Luis Carlos Sales

Universidade Federal do Piauí, Brasil

Luiz de Sousa Junior

Universidade Federal da Paraíba, Brasil

Luiz Fernandes Dourado

Universidade Federal de Goiás, Brasil

Magna França

Universidade Federal do Rio Grande do Norte, Brasil

Marcos Edgar Bassi

Universidade Federal de Santa Catarina, Brasil

Maria Angélica Pedra Minhoto

Universidade Federal de São Paulo, Brasil

Maria Beatriz Luce

Universidade Federal do Rio Grande do Sul, Brasil

Maria Dilnéia Espíndola Fernandes

Universidade Federal de Mato Grosso do Sul, Brasil

Nelson Cardoso do Amaral

Universidade Federal de Goiás, Brasil

Nicholas Davies

Universidade Federal Fluminense, Brasil

Robert E. Verhine

Universidade Federal da Bahia, Brasil

Romualdo Portela de Oliveira

Universidade de São Paulo, Brasil

Rosana Gemaque Rolim

Universidade Federal do Pará, Brasil

Rubens Barbosa de Camargo

Universidade de São Paulo, Brasil

Theresa Adrião

Universidade Estadual de Campinas, Brasil

Tristan McCowan

University of London, Reino Unido

Vera Jacob

Universidade Federal do Pará, Brasil

Vera Peroni

Universidade Federal do Rio Grande do Sul, Brasil

Vitor Henrique Paro

Universidade de São Paulo, Brasil

\section{Equipe editorial}

Apoio ao Comitê Editorial: Caio Cabral da Silva

Diagramação, Revisão de português e normalização: Edson Leonel de Oliveira

Revisão de inglês: Sabrina Ferreira

Fineduca - Revista de Financiamento da Educação

Associação Nacional de Pesquisa em

Financiamento da Educação

e-mail: revista.fineduca@gmail.com | site: http://seer.ufrgs.br/fineduca 